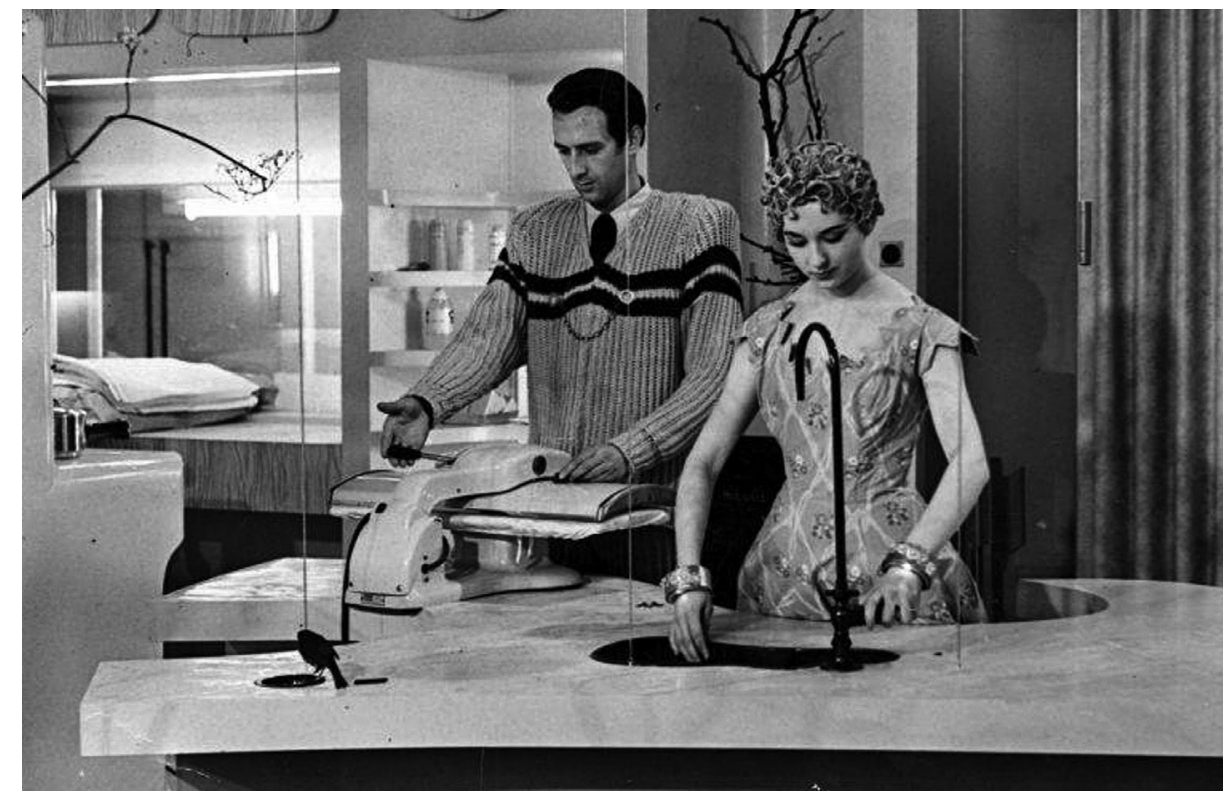

$\wedge$ FIG. 1. Smithson Family Collection

\title{
De habitar a morar: el tiempo en la arquitectura
}

\section{Álvaro Galmés Cerezo}

Recibido 2016.12.08 ::: Aceptado 2016.12.23 DOI: 10.5821/palimpsesto.16.4857

\section{abitar se ha convertido en uno de los objetos de análisis más desarrollados de la crítica arquitectónica de los últimos años, y sin embargo poco sabemos sobre la forma en la que se ha ido modelando en la modernidad este concepto y, sobre todo, a dónde nos está llevando. En el presente artículo pretendo llevar a cabo una reflexión, basándome en el pensamiento filosófico contemporáneo, sobre el contenido de la acción de habitar. El objetivo no es meramente una aclaración conceptual, sino facilitar la actuación de los arquitectos en su trabajo, siguiendo la frase de Heidegger cuando dice que "construir es habitar".}

Es importante tener en cuenta, en el rápido repaso que vamos a hacer sobre la historia de este concepto, que la pre-modernidad no tiene un corpus extenso y claro sobre el habitar. Sus preocupaciones arquitectónicas eran de otra índole, y hasta el romanticismo, con el desarrollo de las ideas sobre la intimidad, el pensamiento y la arquitectura no se preocuparon de estos temas. Así pues, solamente podemos empezar a desentrañar qué significa habitar desde la modernidad arquitectónica.

A principios del siglo XX con Tessenow, Bruno Taut, etc., se pusieron las bases de una reflexión sobre el individuo y de cómo éste ocupa el espacio construido. Pero el primer arquitecto que tiene un cuerpo teórico escrito con cierta consistencia sobre este tema es Le Corbusier. Es cierto que escribió casi de todo y que cualquier idea de la arquitectura moderna se puede decir que tuvo un punto de inflexión en sus escritos; sin embargo, considero que con respecto al "habitar" tuvo una especial sensibilidad en el desarrollo teórico y, con mayor o menor fortuna, también en sus proyectos. Podemos ver esa sensibilidad hacia el ser humano, que ocupa la arquitectura, en sus dibujos: en ellos aparecen interiores habitados, con personas realizando alguna actividad concreta, se ve un deseo de ir más allá de la forma para reflexionar sobre el hombre. Así pues, proyectos, escritos y, sobre todo, estos dibujos, configuran el primer corpus consistente de la reflexión sobre el habitar en la modernidad.

El otro momento importante que podemos considerar dentro de esta reflexión sobre el habitar es el pensamiento de los miembros del Team X, esencialmente representado por Aldo van Eyck y Alison y Peter Smithson. Estos últimos le dan un impulso muy importante a esta idea y, además, con una intuición muy penetrante, desarrollan el concepto de "Época heroica" de la arquitectura, para hablar de Le Corbusier o de
Mies, considerando su propio pensamiento ajeno ya a esa época y dentro de una visión del habitar centrado en el día a día de las personas. Por otro lado, las imágenes de los colegios de Aldo Van Eyck en las que los niños juegan dentro de las aulas, o en los pasillos, representan un excelente ejemplo de esta nueva visión de una arquitectura habitada hecha para el juego y el placer. Sin embargo, esta aparente cotidianeidad de la vida irrumpiendo en la arquitectura es algo que en otros momentos ha sido muy difícil de ver, sobre todo en la época heroica, ya que la pureza con la que se quería mostrar la arquitectura excluía signos ajenos que pudiesen distraer al observador.

El último punto de inflexión no pertenece ya a la arquitectura sino a la filosofía. Aparece con la conferencia que Heidegger dio en 1956, que ha llegado a nosotros con el título de "Construir habitar y pensar" y cuyo objetivo era hacer reflexionar a los profesionales de la arquitectura, en una Alemania que en aquel momento y que corría el riesgo de privilegiar los plazos en detrimento del pensamiento. En ella, como ya hemos dicho anteriormente, el filósofo se plantea la esencia del "Construir" llegando a la conclusión de que ésta se encuentra en el propio hecho de "Habitar", y mediante un pormenorizado análisis del lenguaje desmenuza los hilos que entretejen estos dos principios.

Así pues, podemos considerar, de una manera esquemática, que la modernidad tiene en estos dos hitos desde el punto de vista de la práctica arquitectónica y en esta conferencia desde la reflexión filosófica, algunos de los momentos más importantes a la hora de entender la evolución del concepto de "habitar".

Por otro lado, para seguir profundizando en esta idea, se pueden plantear tres preguntas que nos ayudarán a entender este concepto.

La primera de ellas es la relativa al lugar. "¿Dónde?" ¿Dónde habitamos? Una pregunta esencial para poder profundizar en el habitar. La respuesta primera que daría un arquitecto del siglo XX sería "en el espacio", hay infinidad de investigaciones, artículos y libros escritos sobre el espacio, intentando desentrañar todos sus matices, aclarando su esencia, etc., y esto es así porque lo consideramos como una conquista de la arquitectura contemporánea. El espacio como lo entendemos actualmente es un concepto que está suficientemente aclarado y sobre el que podemos rastrear su origen desde el punto de vista conceptual en la filosofía hegeliana, concretamente en la parte que se ocupa de la arquitectura de su libro "Estética", en la que dice:

"La simple diferencia entre la construcción en madera y en piedra no tiene importancia, no siendo esta diferencia relativa sino a la manera de limitar un espacio, de formar un recinto destinado a un fin religioso o humano (...) Espacio semejante puede obtenerse cavando masas ya sólidas, o, viceversa, construyendo muros y techos que formen un recinto." ${ }^{2}$

Este texto de finales del siglo XVIII y que ya prefigura con cierta claridad lo que va a ser el concepto de espacio para toda la modernidad, es la respuesta que da la modernidad a la pregunta que nos hemos planteado más arriba. A la pregunta de "¿dónde habitamos?" la respuesta es: en este espacio prefigurado intelectualmente por Hegel y desarrollado conceptualmente en la primera mitad del siglo XX. Los arquitectos, por lo tanto, construimos espacio, vibramos con él, de la misma forma que esperamos que vibren los habitantes que lo ocupan, aunque quizá éstos lo hagan en frecuencias distintas a las nuestras.

La siguiente pregunta que hemos de hacernos es la de “¿cómo?", ¿cómo se habita en la arquitectura? Esta pregunta es la que tiene una respuesta más compleja, pero podríamos responderla, aun parcialmente, apelando al "uso". A finales del siglo XIX se empieza a gestar el "funcionalismo" que el movimiento moderno irá desarrollando paulatinamente. El término "usuario" para designar al ocupante de la arquitectura, el concepto de "uso", es una conquista del siglo pasado. El funcionalismo empezó a generar una arquitectura preocupada por cómo se ibo a vivir on ella, lo que condujo ar en el interior consecuentemente en el habitante como destinatario de esa arquitectura "usable". Podemos decir que este concepto se genera antes en la arquitectura que en la filosofía, aunque durante el siglo XX la filosofía del uso se tematiza con la aparición del libro de Heidegger "Ser y tiempo", en el que dice:

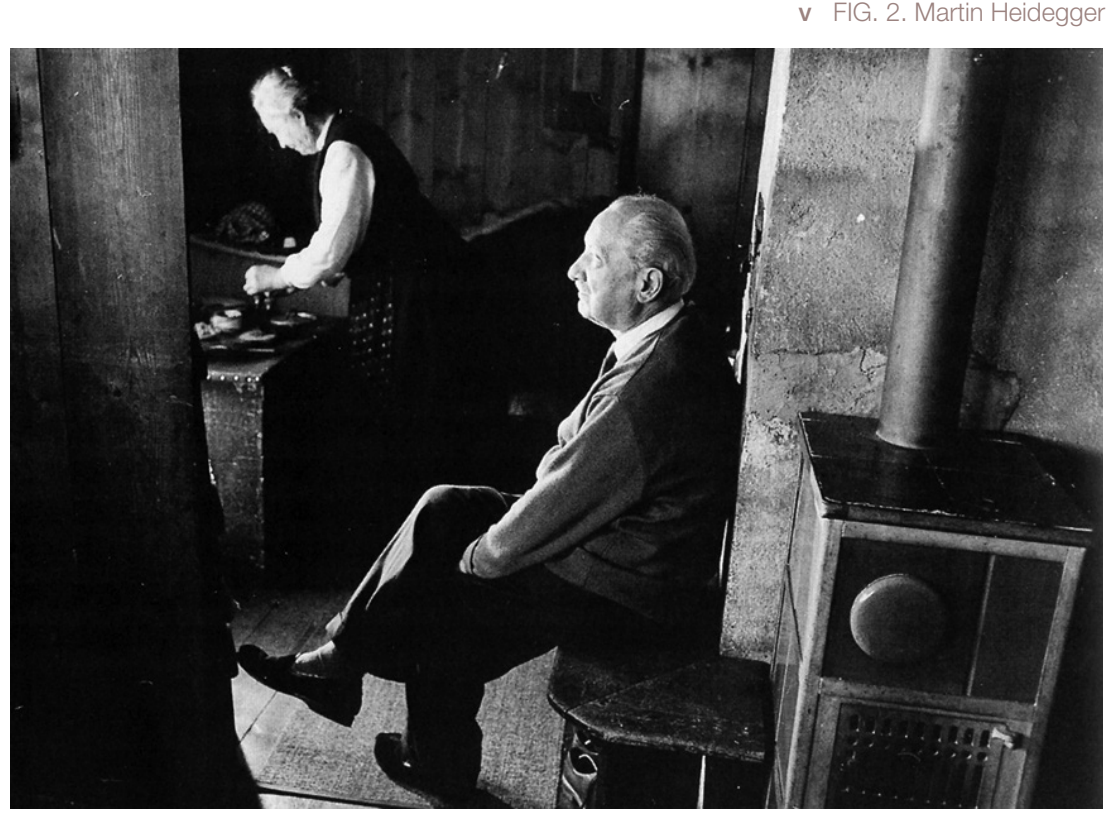


"La obra que se quiere producir, y que es el para-qué del martillo, cepillo y aguja, tiene, por su parte, el modo de ser del útil. El zapato es para llevarlo (útil zapato), el reloj, para ver la hora. La obra que comparece con prioridad en el trato de la ocupación - la que se elaborahace comparecer conjuntamente, en el uso al que por esencia está destinada, el para-qué de su empleabilidad. Por su parte, la obra ya hecha sólo es en base de su uso y del complejo remisional de entes descubiertos en éste." ${ }^{3}$

Heidegger desarrolla aquí la relación que establece el ser con el mundo, y con los objetos que encontramos en él, señalados como "útiles"; lo que el hombre tiene "a la mano" son las "herramientas", de ahí que nosotros podemos asentar en una base ontológica nuestro concepto de función en la arquitectura. La arquitectura, la casa, se nos presenta como una hiper-herramienta, algo que se nos ofrece al uso, como utilizamos un auditorio, como utilizamos un museo, etc.

La tercera pregunta a la que hemos de responder es "¿quién”, "¿quién es que el que habita la arquitectura?" La modernidad defenderá que ese sujeto que habita arquitectura es "el hombre universal". No siendo esta idea original de Le Corbusier, quizá el Modulor ${ }^{4}$ sea la mejor materialización de la misma: un individuo genérico, con unas proporciones estandarizadas, y sin individualidad propia. Este esfuerzo ímprobo a la hora de definir y sistematizar esa idea de hombre universal, de definir sus proporciones y la forma de sus movimientos al actuar, va a suponer que el espacio, al estar diseñado para el uso de este "ser universal", debe tener unas características dependientes de las proporciones y movimientos de éste.

Con la respuesta a estas tres preguntas es posible hacerse una idea bastante aproximada de lo que significa habitar para la modernidad, $y$, en cierto sentido, de algo que todavía en el siglo XXI permanece anclado en nuestro inconsciente.

La palabra habitar viene del latín habitare, frecuentativo de habere (tener), esto es "tener de manera reiterada". De aquí surgen las palabras catalanas "havers", "hàbit"; o las castellanas: "habitual", "habitáculo", etc. Por tanto vemos que desde el punto de vista de la etimología la palabra "habitar" está muy vinculada al "tener", al hecho de poseer. Este es un origen que no presupone una actuación dinámica por parte del sujeto de la acción y sí una posesión, algo distante, por ello, del concepto de uso y de usuario que postula la arquitectura en la modernidad. Los aspectos relacionados con el frecuentativo y por tanto con la idea de "generar hábitos" responden mejor a este concepto fraguado en el siglo XX. Aun así, la dependencia de la raíz "habere" nos impulsa a buscar un nuevo referente que represente mejor nuestra idea.

Michael De Certeau en su libro "La invención de lo cotidiano" medita sobre la carestía del lenguaje con respecto a las prácticas habitacionales que se desarrollan en la actualidad, y dice:

"Nuestras categorías de conocimiento son todavía demasiado rústicas y nuestros modelos de análisis muy poco elaborados para permitirnos pensar en la abundancia inventiva de las prácticas cotidianas. Tal es el motivo de nuestro pesar. Nos maravilla que nos falte tanto para entender las innumerables astucias de los "héroes oscuros" de lo efímero, caminantes en la ciudad, habitantes de los barrios, lectores y soñadores, pueblo oscuro de las cocinas." 5

Así pues, en respuesta a esta idea de De Certeau, nos debemos plantear cuáles son los rasgos más sobresalientes que debería incluir cualquier definición de "habitar" en la actualidad. La primera característica que consideramos necesario incluir es la del "tiempo", cualquier locución que representase esta acción que hasta ahora hemos definido como "habitar" debería tener implícita su dependencia temporal. Karsten Harries en su artículo "Ios edificios y el terror del tiempo" nos habla de la relación entre la arquitectura y el paso del tiempo.

"La arquitectura no trata solo de la domesticación del espacio, sino que constituye una profunda defensa contra el terror del tiempo. Su lenguaje es fundamentalmente el lenguaje de la realidad intemporal." ${ }^{6}$

Y Luis Moreno Mansilla, en el marco de una conferencia sobre Enric Miralles vertida en Barcelona poco antes de morir, pone de manifiesto, también, la importancia del tiempo para la experiencia de la arquitectura:

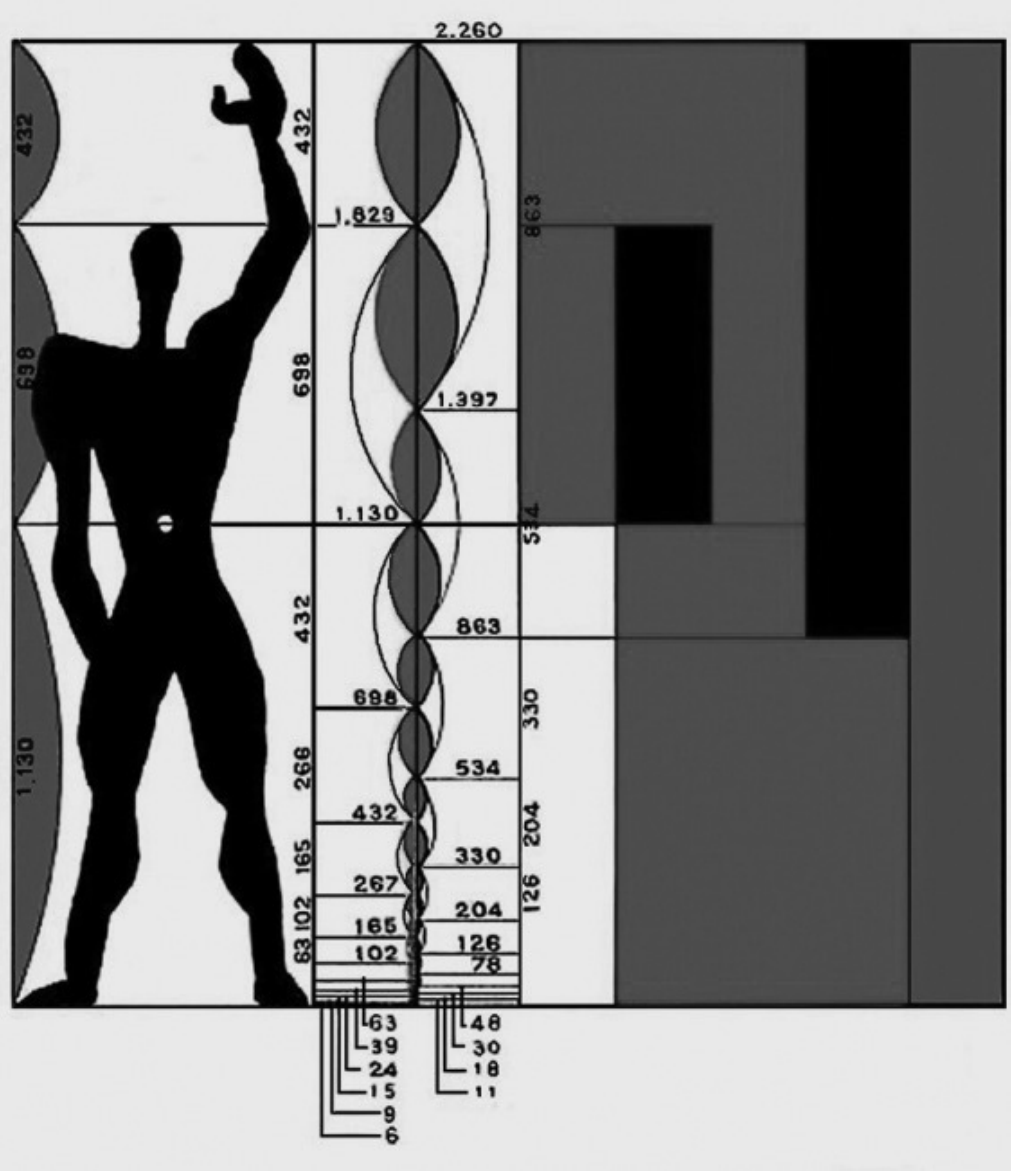

FIG. 3. Modulor. Le Corbusier Obras Completas

“....sospecho que el espacio, en realidad, no forma parte de nuestras preocupaciones vitales, solo el tiempo, que se derrama y escapa entre los dedos cuando intentamos atraparlo..." 7

Creo que ya no deberíamos pensar en la arquitectura sólo como espacio, que no podemos entender qué es habitar sin pensar en el tiempo. El espacio por sí sólo no nos brinda la suficiente complejidad como para entender este constructo complejo. Luis Moreno Mansilla nos ofrece una de las claves que ha conquistado la arquitectura del siglo XXI y es que el espacio no es lo más importante para los habitantes y que, en cambio, sí lo es el tiempo, ya que éste forma una parte relevante de sus preocupaciones vitales. Por su parte Harries nos da otra de las claves, al hablar del terror del tiempo y de la capacidad que tiene la arquitectura para aislarnos del tiempo inexorable del afuera. Estos textos no son más que dos ejemplos de la infinidad de referencias que aparecen en la crítica arquitectónica de los últimos años sobre la importancia del tiempo en la arquitectura y especialmente en el campo de la vivienda. El propio término "vivienda" define aquello que ha de ser vivido en el tiempo, como la "agenda" es aquello que se tiene que agendar, que se tiene que hacer.

Así pues, este constructo que hemos definido hasta ahora por la palabra "habitar" se revela en ese corsé estático y atemporal, y busca un nuevo término en el que pueda encontrarse mejor reflejado.

Para ello hemos de volver al diccionario etimológico y en él encontramos el verbo "morar" que procede del latín morari: detenerse, retardarse, entretenerse, obrar con lentitud; y por extensión: pararse, permanecer y residir. Además está asociado al verbo memorari (recordar) y a mos, moris (manera de vivir). De este verbo en italiano y en francés derivan los términos "dimorare" y "démeurer", que no se han asociado, como sucede en castellano y en catalán, simplemente al concepto de retardar, sino que mantiene el mismo sentido de quedarse en un lugar esto es de "morar" y "habitar". Derivados de esta raíz en catalán encontramos "moratòria" y "morós" y en castellano "morada" y "demorarse" en la acepción de "retardar". En cuanto al sentido de recordar: "memòria o "memorable". Y como maneras de vivir: "moral" o "moralidad". Por lo tanto encontramos tres ideas asociadas a este término que, a mi juicio, reflejan mejor el concepto que la contemporaneidad tiene de esta acción. Podríamos decir que en el siglo XXI esta idea está asociada a detener en la interioridad el tiempo inexorable del exterior; a mantener una memoria de la identidad familiar; y a establecer una adecuada manera de instalarse en el mundo, de actuar, esto es, a formar una moral.

Con respecto a la primera acepción, vinculada con la detención del tiempo, encontramos un texto de Pallasmaa que ilustra muy claramente esto que estamos intentando explicar:
"Sin embargo, otra tarea fundamental del arte de construir es defender el silencio y la lentitud natural de nuestro mundo experiencial. La arquitectura posee la capacidad de reestructurar y alterar nuestra experiencia temporal: puede ralentizar, detener, acelerar o invertir el flujo del tiempo experiencial." 8

Es ese flujo del tiempo de la experiencia el que atañe a la arquitectura. La idea de retardar la percepción del tiempo como un componente esencial del "arte de construir" es una idea que debería ser clave en la arquitectura doméstica contemporánea. Hay un dicho que se repite comúnmente en la experiencia del habitante ordinario cuando se encuentra gozoso en una casa, sea esta propia o ajena, y es que después de haber experimentado el propio morar, dice: "parece que en esta casa pasa el tiempo de otra manera". Esta expresión espontánea refleja, sin embargo, una actitud muy clarificadora del éxito de la morada: la capacidad de despertar en el habitante un tiempo de la interioridad distinto al paso del tiempo del mundo exterior.

La segunda acepción de la raíz "morare" la vincula con aspectos de la memoria. Para entenderla echamos mano, de nuevo, de un texto filosófico para así aclarar cuál es la relación que se establece entre la casa vivida y la memoria.

"Lo que constituye la profundidad de las casas de la infancia, la impresión que dejan en el recuerdo, es evidentemente una estructura compleja de interioridad, en la que los objetos pintan ante nuestros ojos una configuración simbólica llamada morada." 9

Vemos pues que para Baudrillard la "morada" no es ni siquiera un espacio físico, sino un espacio mental. La morada no es solamente un sustrato material, no es solamente algo externo, sino que, como bien dice Baudrillard, es una constelación de recuerdos, de sensaciones y de emociones que se van almacenando en la memoria desde la infancia. Por lo tanto, la vivienda ya no está solo hecha de acero y hormigón sino que también se construye con la memoria de los habitantes.

La tercera acepción es la vinculada a la "moral", una acepción compartida también con la palabra "habitar" de la que deriva "hábito". Así pues, y siguiendo lo que dice Jose Luis Pardo en su libro sobre la intimidad:

"Únicamente puede compartirse en la intimidad, porque no hay más intimidad que la compartida, eso, el ser compartida, es lo que la hace auténtica." 10

Entonces para que exista intimidad tiene que haber una moral compartida. Aquí aparece el concepto de la "hospitalidad" (que ya desarrollé en un libro publicado anteriormente con el nombre de Morar: Arte y experiencia 
de la condición doméstica) que podríamos definir como el de la morada ofrecida a los demás; y que su cultivo constituye la más alta conquista de la vivienda.

Una vez desarrollado el significado del término "morar" apoyándonos en su etimología, vamos a intentar responder a esas tres preguntas que nos hacíamos respecto al concepto de "habitar".

La primera de ellas era la de "¿dónde?”, que la modernidad había respondido "en el espacio". Proponemos ahora responder con el concepto de "atmósfera" que aunque ha sido demasiado reproducido en la reflexión arquitectónica actual y quizá no adecuadamente delimitado, bien utilizado puede sernos muy útil para poner al día nuestras ideas. Vamos a referirnos a él remitiéndonos al sentido que le da Gernot Böhme, que a su vez basa sus ideas en el concepto de "aura" acuñado por Walter Benjamin. A partir de este principio, Böhme desarrolla su concepto de atmósfera, y dice:

"La atmósfera es la realidad común que se establece entre el receptor y lo percibido."

Por lo tanto, la primera idea que surge de este concepto es que esta realidad no se encuentra en el exterior del mundo, ni tampoco en el interior de los individuos, se ubica en ese espacio intermedio o común, entre el observador y lo observado. Podemos decir que es, entonces, el vínculo que se establece entre el mundo exterior y la forma de percibirlo. La segunda cita de este mismo artículo dedicado por Böhme a las atmósferas dice lo siguiente:

\section{"La percepción incluye el impacto afectivo de lo observado (...). El "objeto" primario de la percepción es la atmósfera. Lo primero e inmediatamente que se percibe no son ni sensaciones, ni formas u objetos o sus constelaciones, como el pensamiento de la psicología de la Gestalt dice; sino atmósferas, contra cuyo fondo la relación analítica distingue} cosas tales como objetos, formas, colores, etc."

El planteamiento de Böhme es claro al afirmar que lo primero que experimentamos ante los estímulos externos no es una respuesta intelectual, sino afectiva, lo primero que percibimos es una "atmósfera" a la que respondemos afectivamente, y sólo en un estadio posterior construimos la realidad circundante mediante formas y objetos.

Böhme plantea pues que la "atmósfera" es una realidad compleja en la que está comprendido el espacio que percibe un individuo determinado y la respuesta afectiva que ese espacio suscita, entendiendo por espacio el conglomerado perceptivo circundante sin excluir lo inmaterial perceptible. Por lo tanto, forma parte de dos realidades diferentes, no pudiéndose reducir a ninguna de ellas. No es sólo el espacio que nos rodea, aunque lo es; pero tampoco es solamente un estado de ánimo subjetivo, aunque esté determinada por el estado corporal de los sujetos que moran en ese ambiente. Considero que esta idea es necesaria para profundizar en la fenomenología del habitar, en tanto en cuanto nos aleja del espacio frío de la geometría, un espacio mensurable y homogéneo; y nos acerca a un entorno experimentado y sentido, en el que podemos intervenir como arquitectos.

La segunda de las preguntas a la que respondíamos cuando intentábamos definir qué era "habitar" era la del "¿cómo?", y la respuesta que le dábamos era el "uso". Propongo, pues, cambiar esa respuesta de "uso" por la de "gozo", por una manera muy determinada de entender el gozo, bien definida por el filósofo Emmanuel Levinas, que en su libro "Totalidad el infinito", expone:

"Vivimos de "buena sopa", de aire, de luz, de espectáculos, de trabajo, de ideas, de sueños, etc.(...). Las cosas de las que vivimos no son instrumentos, ni aun utensilios, en el sentido heideggeriano del término. Su existencia no se agota en el esquematismo utilitario que los diseña, como la existencia de martillos, agujas o máquinas. Son siempre, en cierta medida aun los martillos, las agujas, y las máquinas lo son - objetos del gozo, que se ofrecen al "placer" (...). Además, mientras el recurso al instrumento supone finalidad y marca una dependencia frente al otro, vivir de... señala la independencia misma la independencia del gozo y de su felicidad que es la señal original de toda independencia." ${ }^{13}$

El arquitecto debe construir entornos que se ofrezcan al gozo en el sentido más profundo de la palabra, la arquitectura no se ha de comportar solamente como un elemento funcional sino que esencialmente es un objeto

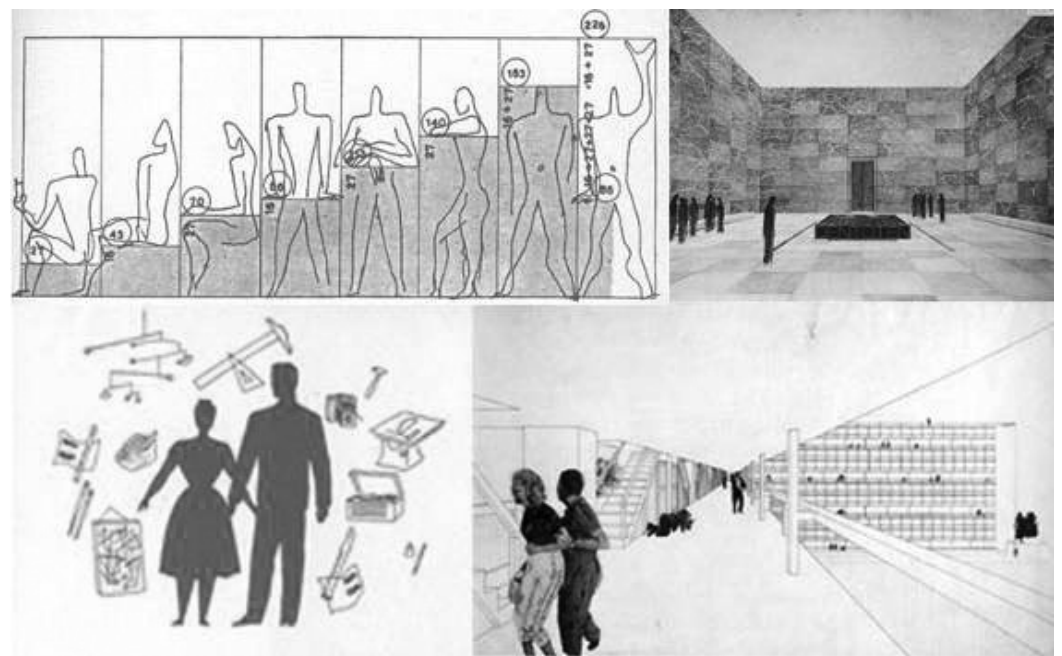

^ FIG. 4. Le Corbusier obras completas; Mies Van Der Rohe; Smithson Family Collection; Eames Office

que se ofrece al gusto, objeto estético en el sentido kantiano. Sin tener que renunciar -como dice Levinas de los martillos, agujas, y máquinas- a la funcionalidad.

Por último vamos a referirnos a quién es el sujeto que mora. Lo que se ha expuesto anteriormente no deja escindido del todo a ese "quién" del contexto, pero aun así podemos intentar definirlo independientemente de su entorno. Si durante la etapa heroica de la arquitectura se definía al habitante como el "hombre universal", ahora, con el asentamiento de la conquista de la subjetividad, vamos a utilizar el término "individuo", la persona vista como entidad irrepetible es ahora el sujeto de la acción. Para ello nos apoyaremos en el pensamiento que desarrolla el filósofo español Javier Gomá en torno al individuo moderno emancipado ya de toda dependencia con respecto al cosmos. Y en una bella frase dice: "El mundo que nos hizo mortales nos dio también la individualidad que somos" ${ }^{14}$. De esta manera vincula el concepto de tiempo -somos tiempo porque somos mortales y el tiempo se nos acaba- con la individualidad del ser humano. Por otro lado, el individuo moderno toma conciencia de su propia experiencia, y hace de ésta el objetivo de su vida. En otro texto nos aclara esta idea del individuo emancipado:

"Importa destacar que el yo moderno es un yo terrestre. El yo se segrega del todo cósmico y, conquistada su independencia, se constituye como una nueva totalidad autosuficiente con deberes hacia sí mismo." ${ }^{14}$

Este es el sujeto que mora en el siglo XXI, un ser emancipado e independiente, que se constituye como una totalidad, a él nos referimos y a él estarán destinadas nuestras obras de arquitectura.

Con estos nuevos parámetros y después de haber reflexionado sobre qué significa el habitar en el siglo XX y en el XXI y cuáles han sido los cambios conceptuales que se han ido operando durante estos casi cien años de arquitectura, podemos llegar a establecer una nueva definición de esta acción, básica para la arquitectura, que hemos denominado "morar". Así pues, podemos decir que la morada genera una atmósfera que permanece latente hasta que es activada por la vida individual, por las intersubjetividades que en ella se desarrollan y que en el día a día definen el carácter de la casa. Esta se ofrece al gozo antes que al uso, y resuena con sus ocupantes. El verdadero significado de la vivienda no lo da el espacio, ni su imagen o su materia, sino la vida que en e tiempo se despliega en ella.

${ }^{1}$ Heidegger, Martin. Construir, habitar y pensar. 2 Hegel, G. W. F. Estética, Tomado de Morales, Jose Ricardo.
Arquitectónica. Biblioteca Nueva; Madrid 1999. p. 136.

${ }^{3}$ Heidegger, Martin. Ser y tiempo. Editorial universitaria: Santiago de Chile, 1997 p. 97.

${ }^{4}$ Le Corbusier. El modulor. Editorial Poseidón; Buenos Aires, 1953.

${ }^{5}$ De Certeau, Michel. La invención de lo cotidiano II. Habitar Cocinar. Universidad iberoamericana. México DF 2000.

${ }^{6}$ Harries, Karsten Building and terror of time en Perspecta, 19 1982, p. 59-69.

${ }^{7}$ Moreno Mansilla, Luis. Citado por Emilio Tuñón en El tiempo que se escapa entre los dedos, Circo 2012-176. p. 6.

8 Pallasmaa, Juhani. Los ojos de la piel. Gustavo Gili; Barcelona,

${ }^{9}$ Baudrillard, Jean. El sistema de los objetos. Siglo XXI de España editores; Madrid: 2010. p.14.

${ }^{10}$ Pardo, Jose Luis. La intimidad. Pre-Textos; Valencia: 2004. p. 145
'Böhme, Gernot. Atmosphere as the Fundamental Concept of a New Aesthetics, Thesis Eleven, Agosto 1993; vol. 36, 1: pp. 113-126.

'Böhme, Gernot. Opus cit.

BIBLIOGRAFÍA

ABALOS, Iñaki. La buena vida: Visita guiada a las casas de la modernidad. Barcelona: Gustavo Gili S. L., 2002.

BAUDRILLARD, Jean. El sistema de los objetos. Siglo XXI de España editores; Madrid, 2010.

BÖHME, Gernot. Atmosphere as the Fundamental Concept of a New Aesthetics, Thesis Eleven, vol. 36, 1: Agosto 1993. COLOMINA, Beatriz. La domesticidad en guerra. Actar:

DE CERTEAU, Michel. La invención de lo cotidiano II. Habitar Cocinar. Universidad iberoamericana. México DF 2000. EAMES, Charles. ¿Qué es una casa? ¿Qué es el diseño? Editorial Gustavo Gili, S. L.; Barcelona, 2010.

GALMÉS, Álvaro. Morar: Arte y experiencia de la condición doméstica. Ediciones Asimétricas: Madrid, 2014.

GOMÁ, Javier. Necesario pero imposible. Taurus; Madrid, 2013. HARRIES, Karsten. Building and terror of time en Perspecta, 19

HEIDEGGER, Martin. Ser y tiempo. Editorial universitaria:

Santiago de Chile, 1997.

LE CORBUSIER. El modulor. Editorial Poseidón; Buenos Aires,

LEVINAS, Emmanuel. Totalidad e infinito. Ediciones Sígueme: Salamanca, 1987.

MARTíNEZ SANTA MARÍA, Luis. El libro de los cuartos. Lampreave; Madrid, 2011.

MORALES, Jose Ricardo. Arquitectónica. Biblioteca Nueva; Madrid, 1999.

NAVARRO BALDEWEG, Juan La habitación vacante. PreTextos; Valencia, 1999. PALLASMAA, Juhani. Los ojos de la piel. Gustavo Gili; Barcelona,
2006.

PARDO, Jose Luis. La intimidad. Pre-Textos; Valencia, 2004.

TUÑÓN, Emilio. El tiempo que se escapa entre los dedos, Circo 2012-176. Madrid, 2012.

\section{ABSTRACT}

Dentro de la arquitectura de la modernidad, uno de los conceptos que más ha influido en su desarrollo ha sido el de "habitar". Sin embargo, cien anos después del inicio de este periodo, las premisas en las que se asentaba este significado se del mismo.

Epresente artículo analiza las principales ideas sobre las que gravito este concepto de habitar y como se han ido sustituyendo Tu significado para Aue se adapte mejor al pensamiento susing icado para que se ade elas, se hace necesaion rede designación y transformar la antigua voz de "habitar", con su carga estática y eminentemente utilitaria, por el término "mora" que por su etimología facilita una comprensión más actual de esa idea, al remitirnos al factor tiempo así como diversas experiencias de interacción espacial.

PALABRAS CLAVE: habitar; morar; tiempo.

ÁLVARO GALMÉS CEREZO es arquitecto por la Universidad Politécnica de Madrid, primer ciclo de psicología por la UNED y Doctor en Arquitectura por la UEM. Su investigación sobre la la participación del habitante en el espacio vivencial ha sido publicada en forma de libro y en revistas especializadas de arquitectura y sociología. 